\title{
Examining Interactive and Metacognitive Processes in Student Learning: Findings from a Hybrid Instructional Environment
}

\author{
Shelly Meyers and Linda D. Feeney \\ Stockton University
}

\begin{abstract}
Author Note
Shelly Meyers, School of Education, Stockton University; Linda D. Feeney, Office of ELearning, Stockton University.

Shelly Meyers is Associate Professor of Education at Stockton University. Linda Feeney is Director of E-Learning and adjunct faculty member for the School of Business at Stockton University.

Correspondence concerning this article should be addressed to Shelly Meyers, School of Education, Stockton University, 101 Vera King Farris Drive, Galloway, NJ 08205. Email:

Shelly.Meyers@stockton.edu
\end{abstract}

\begin{abstract}
This study examines the interaction behaviors and metacognitive behaviors of graduate students in the online portion of a flipped classroom. For their time outside the face to face classroom, students were given the choice of two online methods for their interactions -- synchronous verbal discussions and asynchronous written discussions. Students were provided a detailed outline for their discussions. Discussions were analyzed and interactive and metacognitive behaviors were categorized and counted. Interaction behaviors and metacognitive behaviors were present in both environments. Synchronous verbal discussions were found to include significantly more interaction behaviors in five of six categories. There was no significant difference in the number of metacognitive behaviors. Students demonstrated the same level of learning behaviors in both environments.
\end{abstract}




\section{Introduction}

In 2006, the U.S. Department of Education conducted a meta-analysis of online learning studies to determine if any trends were evident. This report was updated in 2010. The update states that "When groups of students are learning together online, support mechanisms such as guiding questions generally influence the way students interact, but not the amount they learn” (p. xvi). This statement was the partial inspiration for the research described in this study. The researchers were curious not only about the effect of "guiding questions" on learning, but also the effect of differences in the online environment. The purpose of this study was to compare the interaction and metacognitive factors between students who engaged in verbal communication within small groups with students who worked alone and submitted responses in written format.

The impetus for the study was the evolution of the instructional model for the School of Education at Stockton University. It had recently evolved from a fully face to face model to an expanded instructional model including face to face, hybrid, and fully online learning experiences. Graduate students embraced the new models because of freedom from time constraints provided by the online environment as well as opportunities to work in groups with other professionals on a flexible schedule. This component of the learning environment lent itself to students' abilities to collaborate with peers through technology and then apply the concepts to their workplace settings, (Putman, Ford, \& Tancock, 2012). In addition, critical thinking and problem solving are significant to the quality of higher education programs. The authors studied these elements through a comparison of these activities in both synchronous and asynchronous instructional formats (Sengul \& Katranci, 2012).

\section{Literature Review}

\section{Preparing for the Adult Online Learner}

When considering the move to online delivery for graduate students, courses must be designed with the adult learner in mind. Characteristics of the adult learner include their desire to determine what they learn, how they acquire and use the knowledge, and ways in which they actively engage in the learning process (Dunlap, Dudak \& Konty, 2012). Faculty who teach adult students are facilitators, not the primary providers of course content. They specify the requirements of the course and guide students to complete assignments independently (Kasworm, 2011). Faculty who teach adult students also encourage them to take risks when solving problems and consider alternatives that may not be obvious. This behavior leads to broadened perspectives and enhanced application of the course content (McDougall, 2015).

Adult learners seek knowledge that is relevant to their experiences. They aspire to solve complex problems in the workplace and work to gain the confidence to tackle challenges they face in real world settings (Yoo \& Huang, 2013; Harper \& Ross, 2011). Motivating factors for adult learners are opportunities for self-management, control of their own learning and sharing their expertise with others so their contributions to the class are of value (Kasworm, 2012; McDougall, 2015; Harper \& Ross, 2011).

Although adult learners seek independence and control in the learning environment, they also want support from the faculty. They choose programs that offer small class size, regular communication with faculty and access to technology and research information (Kasworm, 2012). They expect help with the technology needed for the online instructional delivery as well as criteria and expectations for content mastery (Yoo \& Huang, 2013). 


\section{Choosing a Hybrid Learning Environment}

McDougall (2015) and Harper and Ross (2011) studied the importance of adult learners' interactions with faculty members and fellow students. These opportunities might include collaborative discussions, problem analysis activities, considering and responding to others' perspectives and using new knowledge immediately in the workplace (McDougall, 2015; Harper \& Ross, 2011). A hybrid model of course delivery addresses these needs with a face to face component and an online component. Regardless of environment, faculty present information and coordinate group interactions among students with case based activities, problem solving and a forum in which to share their own expertise with each other (Barak \& Dori, 2009).

Within a hybrid class designed by the authors, there are two interconnected theories of instruction - constructivism and the flipped classroom. Each is an alternative approach to the traditional face to face method of instructional delivery.

\section{Constructivist Theory of Learning}

Constructivism refers to the ways in which an individual makes sense of new information presented. Students in receipt of unknown concepts or skills rely on past experience to connect the new with the known (Bas, 2012). Students in constructivist classes have opportunities to collaborate with others as they discuss real world issues and their own experiences. They share information and learn from each other by exploring alternative solutions to problems found in the workplace (Barak \& Dori, 2009). Pecore (2013) identifies the common principles that educators follow in the constructivist classroom students are encouraged to take responsibility for their learning, to learn about their metacognitive processes, and to understand the complexity of their thinking.

The constructivist learning environment must be conducive to facilitating cooperative participation among students to foster critical thinking. Teachers construct activities based on real life experiences and challenges. Students then collaborate, sharing perspectives to create solutions to problems or evaluate existing situations and propose alternatives where they "think out of the box" (Sengul \& Katranci, 2012). Each student contributes to the success of the product with his or her individual task associated with the whole assignment (Sengui \& Katranci, 2012).

Faculty in higher education present problems that are content related and students explore complementary solutions based on their own experiences (Pecore, 2013). However, they must be proficient in content, pedagogy and use of technology (Wetzel, Foulger, \& Williams, 2008). Assignments, designed to be real world in nature, may be presented in varied formats- visual, computerbased, written, oral, and hands-on demonstrations (Bas, 2012; Putman, Ford, \& Tancock, 2012; Park, Kim, \& Yu, 2011).

\section{Benefits of the Constructivist Classroom}

Research suggests that students benefit from the constructivist instructional model in several ways. They demonstrate their ability to think critically, solve problems, develop arguments, substantiate solutions and acquire knowledge strengthened by interactions with fellow students (Sengul \& Katranci, 2012). They take responsibility for personal learning, and demonstrate motivation to achieve success in their academic subjects (Barak \& Dori, 2007).

Within the constructivist classroom, faculty guide students as they engage in connecting and organizing new information to their previous knowledge base as they collaborate with others in the class and apply their learning to new constructs, further expanding their learning (Mishra, 2014). The value of the interactions with classmates is the exposure to different viewpoints; acknowledging differences that are essential in today's multicultural world (Putman, Ford \& Tancock, 2012; Jong, Chen, Tse, Lee \& Lee, 2010). Higher order thinking results when students participate in group activities where they are 
presented with a problem or issue to discuss and, before a solution is reached, they analyze and synthesize the information, make a connection to a real world situation, and create the resolution (Balaji \& Chakrabarti, 2010).

Through this mode of teaching and learning, students are prepared for life after school as they focus on problem solving, maintaining a flexible worldview where all ideas are valued, and helping others apply new information to previous background knowledge (Balaji \& Chakrabarti, 2010). Constructivist methods also direct students' learning when they choose topics for assigned course work relevant to their profession (Dunlap, Dudak \& Konty, 2012). Another benefit is that students are afforded opportunities to participate in activities that reflect their own metacognitive processes (Pecore, 2013).

\section{Challenges and Limitations of the Constructivist Classroom}

The constructivist classroom model poses difficulties with student assessment. The challenge to assessment presents itself primarily with formative assessment measures. The nature of constructivist learning emphasizes process rather than a final product. The dilemma here is the assessment tool that will determine skills mastered and those in need of remediation. Therefore, when faculty assess, they look at the students' active learning in addition to the result of the learning which is a two-pronged process (Mishra, 2014).

Key to the constructivist design, a second assessment matter that must be resolved is the method by which faculty measure progress as students work in cooperative groups. Teachers recognize that students learn differently and, because they are not directly participating in the learning, faculty need a creative approach to non-traditional assessment (Swarnay 2012). Suggestions for assessment include portfolios, reflective exercises, rubrics, and surveys (Misha, 2014; del Moral, Cernea \& Villalustre, 2013).

Cooperative learning endeavors in the constructivist classroom require faculty to establish clear guidelines and expectations as well as criteria for assessment. This adds to the time faculty spend teaching and grading (Putman, Ford, \& Tancock, 2012). Although research supports group learning as a means to engage students in constructing their own learning, many students prefer working alone. Faculty need to consider the individual preferences of students and might modify the learning environment to accommodate these differences (Breneiser, Monett \& Adams, 2012).

\section{The Flipped Classroom}

Researchers describe the flipped classroom environment as one in which students access technology for the receipt of new information provided by the teacher outside of the scheduled class. During class time, students engage in activities where they apply new knowledge to their own experiences (Keane, 2014; Roehl, Reddy, \& Shannon, 2013). Moving the lecture away from the classroom through a recorded lecture platform does not replace teacher instruction but enhances the presentation and allows students to use the time in class with the teacher to participate in activities related to course content (Strayer, 2012). The primary focus of the flipped classroom is to assist teachers and students in ongoing communication, whether written or oral, as they cooperate in active learning involvement and receive prompt feedback from the teacher and fellow students (Wang \& Morgan, 2008; Lo \& Monge, 2013; Einfield, 2013).

The graduate students included in this study, are motivated to accomplish tasks, take responsibility for their own learning, and use higher level thought to do so (Lo \& Monge, 2014). Keane (2014) notes that reasons for an increase in student academic progress include the flexibility of course delivery and assignment completion, interest in the task, and the support of other students, as a supplement to teacher support. Objectives are aligned with each assignment and the teacher ensures all expectations and assessment criteria are established (Wadley, 2010). 


\section{Benefits of the Flipped Classroom}

The benefits of the flipped classroom closely resemble those of the constructivist orientation. Students work together in a non-critical, supportive environment and take risks as they work independently (Wang \& Morgan, 2008). They become more aware of their own metacognition as they engage in authentic activities related to their current knowledge base (Lo \& Monge, 2013) Learning is ongoing and fluid and, as new content is introduced, students embrace it and integrate into real world contexts (Himelo-Silver, Chernobilsky \& Jordan, 2008). Students are no longer passive recipients of information, rather they are active in their own learning (Lo \& Monge, 2013). Lastly, the flipped classroom provides more time for hands on activities that capture students' interests and motivate them to succeed in their academic subjects (Enfield, 2013).

\section{Challenges and Limitations of the Flipped Classroom}

Reports from the literature suggest that students are less satisfied with using technology and the amount of work required before each class session. They expressed concern that students were often reluctant to listen to a recorded lecture and frequently waited until the actual scheduled class (Herreid \& Schiller, 2013). This failure to prepare for class in advance left them lacking in the information needed to contribute to class activities.

Another interesting point made by Wang \& Morgan (2008) is that students are required to use verbal or written discussion responses to the teacher's lecture questions, but written discussions lacked the spontaneity and the higher order thinking. Faculty also did not embrace the flipped classroom but preferred the traditional course arrangement (Roehl, Reddy, \& Shannon, 2013; Lo \& Monge, 2013). They indicated that the amount of preparation time and the hours spent before class responding to students' questions and answers was unrealistic when teaching several courses with the flipped classroom format (Francl, 2014).

\section{Examining the Hybrid Environment at Stockton University}

The graduate level courses examined in this study employ a hybrid format combining the flipped classroom with constructivist theories. Hutchings and Quinney (2015) describe the flipped classroom as both face to face instruction and distance learning. Students assume responsibility for reading and reviewing course content delivered via technology and participate in activities where they apply the concepts in face to face interactions with classmates. The actual learning takes place in constructivist based theory. Faculty guide students as they make connections between the content and their prior knowledge and construct new knowledge in ways that reflect their individual work environments (del Moral, Cernea \& Villalustre, 2012). Class time is used for student/faculty interaction. Instructors clarify concepts, respond to questions and facilitate small group activities where content is applied to real world experiences.

Online discussion forums enable students to meet, with or without faculty presence, as they collaborate on assignments, solve problems, analyze case studies and ask and answer each other's questions. Discussions were conducted using both asynchronous discussion boards and synchronous meeting rooms. Students were given the option of choosing their preferred tool.

Students enrolled in the graduate level special education courses received all instructional materials and resources within the Blackboard learning management system. Faculty uploaded syllabi, exams, rubrics, supplemental readings and pre-recorded lectures, and textbook slide decks. Students selected their own learning activities, given a framework and criteria to follow. They made choices relevant to their classroom experiences. 
Reflection is a key component for adult learning and is important in the course format (Barak \& Dori, 2009). Students critically analyzed the course content and considered aspects that have significant impact on their prior knowledge. They then worked to synthesize the new information as they connected it with what they already knew. Lastly, students evaluated the value of the new information and used it to enhance current practice.

Students were required to listen and respond to recorded lectures before each class session. They met online in small groups to answer the questions posed in the lecture, share their relevant experiences, and discuss the application of the content to their own classrooms. Students had the option of responding to each other either in a written format through an asynchronous discussion tool within Blackboard or in an online synchronous meeting room using Blackboard Collaborate. Discussions in Collaborate were recorded for faculty review.

The instructor read the written responses, listened to the verbal recordings and replied to all students' comments and questions. Student questions provided direction for further instruction during the following face to face class session. Additional small group work included analyzing and critiquing case studies and supplemental readings that enhanced content and provided additional opportunities for students to think critically and apply the new knowledge to their current teaching positions.

\section{Data Collection}

The sample consisted of one hundred twenty-five graduate students enrolled in three courses in the special education program. These courses were EDUC 5331, Behavior Management and Disabilities, EDUC 5320, Survey of Moderate and Severe Disabilities and EDUC 5339, Collaboration and Inclusion. These courses were offered over a two-year period, September 2013 through May 2015.

In addition to the data collected for analysis, the students were surveyed at the conclusion of each semester. They were asked to comment on the format they preferred for discussing course content. There were twelve questions for students to consider regarding the value of interactions with group members versus working alone.

Questions included items such as "Do I generally apply information from the course content to my current teaching practice?”, “Do members of my group compare and contrast relationships, draw inferences from others' responses to determine relevance of the questions being asked by the instructor as well as the assigned readings?”, "When working in my group, do the topics elicit emotional responses in me or members of my group?", and "Given the opportunity to respond to questions and assigned readings through verbal communication or written, which do you prefer and explain why?" These responses were not subjected to formal analysis but provide insight into the student experience. Highlights form this survey are presented in the discussion section.

The students selecting synchronous discussion were divided into small groups consisting of two or three members. The students selecting asynchronous discussion remained in a single group in each section. The synchronous communications sample included forty-four instances of recorded conversations. The asynchronous communications sample included thirty-three instances of online discussion postings.

The artifacts generated by the students - recorded discussions and written discussion postings were coded and analyzed to determine if synchronous and asynchronous communications exhibited differences. Two major areas of communication were examined: interaction and metacognition. 
Categories of interaction behaviors were emotional content, communication processes, worldview, self-perception, other perception, and separation. The categories of interaction were the product of an unpublished study. A public, online discussion board available to all members of a university campus community was examined (Feeney, 1999). A representative sample was coded using the axial coding method. Axial coding is a qualitative research method that categorizes behaviors and interactions to provide researches a schema for understanding the contexts in which the behaviors occurred (Saldana, 2011, p. 85). From the coded sample, a protocol was developed for analyzing electronic discussion. This protocol was further refined to create the coding categories used in this study.

A coding sheet was developed to classify and count the student communications in the synchronous and asynchronous environments. Table 1 provides the detailed codebook for each category of behavior. Where appropriate, differences in asynchronous and synchronous behavior are noted. For example, emphasis, capitalization and punctuation were counted in the asynchronous environment while tone of voice, pitch, and volume were counted in the synchronous environment.

Table 1: Interaction Categories and Behaviors

\begin{tabular}{|c|c|}
\hline Thematic Dimension & Representative Behavior \\
\hline \multirow[t]{3}{*}{ Emotional Content } & $\underline{\text { Synchronous }}$ \\
\hline & $\begin{array}{l}\text { Participants use tone of voice, pitch, volume, pacing (faster or slower } \\
\text { than average), non-verbal expressions (e.g., laugh, groan, gasp) to } \\
\text { add emotional content to their discussion. } \\
\text { Asynchronous }\end{array}$ \\
\hline & $\begin{array}{l}\text { Participants use typefaces, colors, capitalization, and punctuation, } \\
\text { emoticons, or images to add emotional content to their postings. }\end{array}$ \\
\hline \multirow[t]{3}{*}{ Communication Processes } & Synchronous \\
\hline & $\begin{array}{l}\text { Participants introduce or review ground rules to maintain civility, use } \\
\text { explanation to prevent or correct miscommunication, give or solicit } \\
\text { feedback, interrupt discussion to clarify or calm. } \\
\text { Asynchronous }\end{array}$ \\
\hline & $\begin{array}{l}\text { Participants introduce or review ground rules to maintain civility, use } \\
\text { explanation to prevent or correct miscommunication, give or solicit } \\
\text { feedback. }\end{array}$ \\
\hline
\end{tabular}

World View

Participants share their views on the real world around them, describe the characteristics of a perfect world, use family/ethnic background to illustrate sources of their worldview, use personal experiences to illustrate sources of their world view.

\begin{tabular}{l} 
Self-Perception $\begin{array}{c}\text { Participants describe their place in the world including perceptions of } \\
\text { past, present, or anticipated events to support their positions. }\end{array}$ \\
\hline Other Perception \\
$\begin{array}{l}\text { Participants describe how they believe they would be described by } \\
\text { others or express their view of how others see them, express feelings } \\
\text { about others outside their personal or professional community }\end{array}$ \\
\hline Separation \\
$\begin{array}{c}\text { Participants describe how they establish and/or maintain separation from } \\
\text { others outside their personal or professional community }\end{array}$
\end{tabular}


The categories of metacognitive behavior included remember, understand, apply, analyze, evaluate, and create. These categories were based on the revised Bloom's Taxonomy (Krathwohl, 2002). Table 2 provides the detailed code book categories of metacognitive behavior.

Because this coding process was untested, the researchers enlisted faculty colleagues to serve as validation and reliability coders. The volunteer coders were provided with a training session to acquaint them with each category and the types of behaviors to be counted. Coding sheets and a representative sample of synchronous and asynchronous behaviors were provided. Unfortunately, insufficient samples were returned and the researchers were unable to run tests for validity and reliability.

As an alternative, a single, impartial third party was enlisted to code the behaviors. This coder was Stephanie Swift, a Graduate Assistant of Shelly Meyers, in the School of Education. She was familiar with curriculum, but not enrolled in any of the courses used for the study. This ensured that the behaviors would be coded consistently and researcher bias would be minimized.

Table 2: Metacognition Categories and Behaviors

Thematic Dimension Representative Behavior

Remember Participants ask and answer questions that demonstrate their ability to recall factual statements to support their positions.

Understand Participants ask and answer questions that demonstrate their ability to categorize, organize, paraphrase, outline, summarize, or interpret information to support their positions

Apply $\quad$ Participants ask and answer questions that demonstrate their ability to clarify, reflect, interpret, generalize, or theorize using information that supports their position.

\begin{tabular}{ll}
\hline Analyze & $\begin{array}{c}\text { Participants ask and answer questions that demonstrate their ability to } \\
\text { identify and describe the dynamics of processes or relationships, compare } \\
\text { and contrast, determine relevance, draw inferences, or distill information } \\
\text { to support their positions. }\end{array}$ \\
\hline Evaluate & $\begin{array}{l}\text { Participants ask and answer questions that demonstrate their ability to } \\
\text { prioritize, assess, validate, defend, and critique information to support } \\
\text { their positions. }\end{array}$ \\
\hline Create & $\begin{array}{c}\text { Participants ask and answer questions that demonstrate their ability to build } \\
\text { new theories, adapt or combine existing methodologies, or invent new } \\
\text { methodologies. }\end{array}$ \\
\hline
\end{tabular}




\section{Data Analysis}

As previously mentioned, the synchronous communications sample included forty-four instances of recorded conversations and the asynchronous communications sample included thirty-three instances of online discussion postings. Because of the small sample sizes and the disparity in sample sizes, parametric testing could not be used. To address these issues, the data was tested using the IndependentSamples Mann-Whitney U Test, a nonparametric analysis. This test ranks the data, computes the average rank of the data points, and analyzes the differences in rank, thus addressing the disparity in sample sizes. (George \& Mallery, 1999, p. 197).

Two-tailed hypothesis testing was selected. There were two null hypotheses:

- Incidents of interactions are not significantly different when comparing the synchronous and asynchronous communications.

- Incidents of metacognition are not significantly different when comparing the synchronous and asynchronous environments.

\section{Results}

As referenced in the introduction, the United State Department of Education concluded that guiding questions influence interactions but do not affect the amount of learning that occurs. (2010, p. xvi). However, the results in this study challenge that conclusion. Student artifacts in this study were generated based on guiding questions and the data illustrates that learning did take place.

Summarizing the raw data, Table 3 lists the number of instances of interactive behaviors and Table 4 lists the number of instances of metacognitive behaviors occurring in synchronous and asynchronous environments throughout the semester. Because of the disparate group sizes, no conclusions should be drawn from the raw count of behaviors. However, the number of responses to these guiding questions do illustrate that learning was taking place and that it took place at all levels of cognitive complexity.

Table 3: A Count of Interactive Behaviors

\begin{tabular}{ccc}
\hline Thematic Dimension & Synchronous & Asynchronous \\
\hline Emotional Content & 585 & 186 \\
Communication Processes & 551 & 236 \\
World View & 604 & 217 \\
Self-Perception & 312 & 210 \\
Other Perception & 397 & 136 \\
Separation & 211 & 111 \\
\hline
\end{tabular}


Table 4: A Count of Metacognitive Behaviors

\begin{tabular}{ccc}
\hline Thematic Dimension & Synchronous & Asynchronous \\
\hline Remember & 208 & 117 \\
Understand & 191 & 144 \\
Apply & 172 & 124 \\
Analyze & 157 & 129 \\
Evaluate & 135 & 112 \\
Create & 84 & 80 \\
\hline
\end{tabular}

Independent-Samples Mann-Whitney $U$ tests were run at a significance level of .05. For interaction behaviors, the null hypothesis was rejected in five out of the six categories. Table 5 includes details on the statistical findings. For metacognitive behaviors, the null hypothesis was retained for all six categories. Table 6 includes details on the statistical findings.

Table 5: Hypothesis Testing Summary - Interaction Behaviors

\begin{tabular}{ccl}
\hline Thematic Dimension & Asymptotic Significance & Decision \\
\hline Emotional Content & .000 & Reject the null hypothesis \\
Communication Processes & .000 & Reject the null hypothesis \\
World View & .000 & Reject the null hypothesis \\
Self-Perception & .351 & Retain the null hypothesis \\
Other Perception & .000 & Reject the null hypothesis \\
Separation & .004 & Reject the null hypothesis \\
\hline
\end{tabular}

Table 6: Hypothesis Testing Summary - Metacognitive Behaviors

Significance

Thematic Dimension

$\begin{array}{cc}\text { Remember } & .098 \\ \text { Understand } & .834 \\ \text { Apply } & .925 \\ \text { Analyze } & .357 \\ \text { Evaluate } & .405 \\ \text { Create } & .178\end{array}$

Decision

Retain the null hypothesis

Retain the null hypothesis

Retain the null hypothesis

Retain the null hypothesis

Retain the null hypothesis

Retain the null hypothesis

In all cases where the null hypothesis was rejected, the rank of the behaviors exhibited in the synchronous sample significantly exceeded the rank of the behaviors exhibited in the asynchronous sample. Although not statistically significant, in the category "Self-Perception" the rank of the behaviors in the synchronous sample still exceeded the rank of behaviors in the asynchronous sample. Details are included in Table 7. 
Table 7: Interaction Behaviors in Synchronous versus Asynchronous Environment

\begin{tabular}{ccc}
\hline & \multicolumn{2}{c}{ Mean Rank } \\
\cline { 2 - 3 } Thematic Dimension & Synchronous & Asynchronous \\
\hline Emotional Content & 52.47 & 21.05 \\
Communication Processes & 48.84 & 24.55 \\
World View & 50.82 & 23.24 \\
Self-Perception & 41.05 & 36.27 \\
Other Perception & 51.12 & 22.83 \\
Separation & 45.25 & 30.67 \\
\hline
\end{tabular}

\section{Discussion}

The examination of student learning in this study was performed after the learning experiences were complete. Counts of metacognitive behaviors indicated that learning took place. What is most important about these numbers, however, is that learning is taking place in both synchronous and asynchronous environments at all levels of Bloom's Taxonomy, not just at the lowest levels.

The conclusion presented by in the US Department of Education report was based on a study titled "The effect of using guided questions and collaborative groups for complex problem solving on performance and attitude in a Web-enhanced learning environment" (Suh, 2006). Suh concluded that the effect of the guiding questions was dissipated by the student interactions with each other. However, the findings in this study - which used guiding questions as the basis for student discussion - contradict this conclusion.

The major difference appears to be the population studied. The students in the Suh study were undergraduate, pre-service teachers. The students in this study were graduate students and practicing teachers. The findings of this study imply that student experience in the field may be an important factor in the impact of guiding questions on the learning process.

The surprising result is the rejection of the null hypothesis for the level of metacognitive behaviors. Students in the asynchronous group who had the time to research, reflect, and edit before posting on a discussion board might logically be expected to demonstrate a higher level of metacognitive behaviors than their peers who were engaged in an extemporaneous discussion. However, there was no statistically significant difference between the two groups.

Student comments in the end of semester survey were very revealing. Although more students indicated that the verbal discussion model was their preference, several students favored writing.

Those in favor of synchronous communications sited the immediacy of feedback,

- "Collaborate discussion allows us to articulate our experiences as they relate to the course content and we can expand from each other's responses that spark other ideas or stories to share."

- $\quad$ "I have more to say about a topic after hearing the opinions of other group members. It also gave me insight into other methods or approaches that can be used with my own students. It helps me solve problems I face in my classroom.” 
freedom of expression,

- "When participating in Collaborate discussion, I feel as though I am more inclined to express my thoughts and opinions more freely. When I write, I am more likely to recall facts and restate what the book or article states, but neglect to apply the concepts to my experiences as a special education teacher."

- "We are also able to 'vent' about issues in education whether they be in district or at the state level."

diversity of opinion and experiences,

- "Collaborate discussion has a voice behind it. I am able to understand a classmate's point of view and beliefs. It is important to challenge ourselves by being open minded to other's experiences and the way other (school) districts do things."

- "When we complete assignments through writing, we do not have other experiences to think about or reflect on and it does not provide us with as much critical thinking when we simply answer questions."

and observation of theory in action.

- "The Collaborate discussions tend to go hand in hand with some of the strategies we learn about in class, for example, learning from our peers and also offering differentiated strategies in how we complete assignments."

- "Learning is a social process and this collaborative approach emphasizes and expands my own learning as I learn together with others.”

Those in favor of asynchronous communications sited a reluctance to interact synchronously with unfamiliar colleagues,

- "I prefer writing my responses or discussing with classmates face to face in class. I find it difficult to communicate with someone online that I do not really know."

- "If you have members with a solid work ethic, it could be beneficial having different perspectives however, if you have members that tend to lack that, it can be frustrating."

concerns over using an unfamiliar technology,

- "I prefer responding in writing because I do not feel comfortable with the technology at this time.”

and flexible scheduling.

- "I prefer to write my responses because I can work at my own pace and on my own schedule. It is difficult to plan with three other people our discussion times when we all work and have other obligations.”

\section{Limitations}

Findings from this study should not be generalized to all populations. Although the results are encouraging, there are inherent limitations: small sample size, narrow population, self-selection, compressed time frame, and the subjective nature of the evaluation.

The sample size, both in number of participants and number of data points, is limited. One hundred twenty-five students were enrolled in the three courses that were analyzed. There were only forty-four synchronous communications in the sample and thirty-three asynchronous communications. 
The student work examined in this study was the product of graduate level, practicing teachers. The work product of students in other disciplines and at other levels of education may produce different results.

The student work examined in this study was created by students who chose their modality of communication. Results may vary when participants are not free to choose between synchronous and asynchronous communications.

The student work product was generated over the course of four semesters. A study of student work product from a longer time period may produce different results.

The final area of concern is the instrument and methodology for counting. Qualitative research, in this case the coding of student behaviors, by its very nature is subjective. In this study coding differences were minimized by employing a third party coder. However, a future coder evaluating the same student work product might find different results. Refinements to definitions of interaction behaviors and metacognitive behaviors may improve potential disparities.

\section{Implications for Future Research}

The possibilities for future research grow out the limitations of the study. Future research should be done with a larger sample and broader population. For more universal applicability, the population should include undergraduate as well as graduate students and students from disciplines outside of education. Undergraduate students will require more direct instruction in the face to face portion of the flipped environment. Their previous learning environments are often more concentrated on lower levels of metacognition and may not have included reflective practices.

The participants in the study were given the option of selecting synchronous or asynchronous interactions. Adult learners often select a learning environment based on convenience. The results using participants assigned to a learning environment should be examined.

Finally, methods for refining the coder training should be explored. In particular, the coding of the synchronous conversations was challenging. Providing the coders with a transcript will cut coding times and make the process more similar to coding the asynchronous discussion. This will allow the researchers to do reliability and validity testing and will enable other researchers to use the instrument and methodology in future studies. 
Examining Interactive and Metacognitive Processes in Student Learning: Findings from a Hybrid Instructional Environment

\section{References}

Balaji, M.S. \& Chakrabarti, D. (2010). Student interaction in online discussion forum: Empirical research from ‘media richness theory’ perspective. Journal of Interactive Online Learning, 9(1), 1-22.

Barak, M., \& Dori, Y. (2009). Enhancing higher order thinking skills among in-service science teachers via embedded assessment. Journal of Science Teacher Education, 20(5), 459-474. doi:10.1007/s10972-009-9141-z.

Bas, G. (2012). Investigating the correlation between students' perceptions on the constructivist learning environment and their academic success in science course with path analysis. Journal of Baltic Science Education, 11(4), 367-377.

Breneiser, J. E., Monetti, D.M., \& Adams, K.S. (2012). The nexus between above average effect and cooperative learning in the classroom. Educational Research Quarterly, 36(2), 42-61.

Del Moral, M.E., Cernea, A. \& Villalustre, L. (2013). Connectivist learning objects and learning styles. Interdisciplinary Journal of E-Learning and Learning Objects, 9, 105-124.

Dunlap, E. S., Dudak, B. \& Konty, M. (2012). A synthesized model of integrating principles of adult learning in the higher education classroom. Kentucky Journal of Excellence in College Teaching and Learning, 19(10), 1019-1035.

Enfield, J. (2013). Looking at the impact of the flipped classroom model of instruction on undergraduate multimedia students at CSUN. Techtrends: Linking Research \& Practice to Improve Learning, 57(6), 14-27. doi:10.1007/s11528-013-0698-1

Feeney, L.D. (1999). Participant observation: An examination of the virtual culture observed in an asynchronous electronic conferencing system. Unpublished manuscript. Widener University, Chester, PA.

George, D. \& Mallery, P. (1999). SPSS for Windows Step by Step. Needham Heights, Massachusetts: Allyn and Bacon.

Francl, T.J. (2014). Is flipped learning appropriate? Journal of Research in Innovative Teaching, 7(1), 119-128.

Harper, L. \& Ross, J. (2011). An application of Knowles' theories of adult education to an undergraduate interdisciplinary studies degree program. The Journal of Continuing Higher Education, 59:161166. doi: 10:1080/07377363.2011.614887

Hmelo-Silver, C., Chernobilsky, E., \& Jordan, R. (2008). Understanding collaborative learning processes in new learning environments. Instructional Science, 36(5/6), 409-430. doi:10.1007/s11251-0089063-8

Herreid, C., \& Schiller, N. A. (2013). Case studies and the flipped classroom. Journal of College Science Teaching, 42(5), 62-66. 
Hutchings, M. \& Quinney, A. (2015). The flipped classroom, disruptive pedagogies, enabling technologies and wicked problems: Responding to the "bomb in the basement”. Electronic Journal of E-Learning, 13(2), 105-118.

Jong, M.S.Y., Chen, W., Tse, A.W.C., Lee, F. \& Lee, J.H.M. (2010). Using posting templates for enhancing students' argumentative elaborations in computer supported collaborative inquiry learning. Research and Practice in Technology Enhanced Learning, 5(3), 275-294. doi: 10.1142/S1793206810000906.

Kasworm, C.E. (2012). US adult higher education: One context of lifelong learning. International Journal of Continuing Education and Lifelong Learning, 5(1), 1-19.

Keene, K. (2013). Blending and flipping distance education. Distance Learning, 10(4), 63-69.

Krathwohl, D. R. (2002). A revision of Bloom's Taxonomy: An overview. Theory into Practice, 41(4), 212-218. Retrieved from http://www.jstor.org/stable/1477405

Lo, C., \& Monge, A. N. (2013). Inclusive, interactive classroom as student-learning facilitator. International Journal for the Scholarship of Teaching \& Learning, 7(2), 1-20.

McDougal, J. (2015). The quest for authenticity: A study of an online discussion forum and the needs of adult learning, Australian Journal of Adult Learning, 55(1), 94-113.

Mishra, S. (2014). Assessment of learners in a constructivist learning environment. GYANODAYA: The Journal of Progressive Education, 7(1), 35-43.

Park, S.H., Kim, M. \& Yu, D. (2011). The effects of learning authenticity on the learning achievements in the online corporate training programme. British Journal of Educational Technology, 42(2), E37E41. doi:10.1111/j.1467-8535.2010.01163.x

Pecore, J.L. (2013). Beyond beliefs: Teaching adapting problem-based learning to preexisting systems of practice. Interdisciplinary Journal of Problem-Based Learning, 7(2), 6-33. doi: 10.7771/15415015.1359

Putman, S., Ford, K., \& Tancock, S. (2012). Redefining online discussions: Using participant stances to promote collaboration and cognitive engagement. International Journal of Teaching \& Learning in Higher Education, 24(2), 151-167.

Roehl, A., Reddy, S., \& Shannon, G. (2013). The flipped classroom: An opportunity to engage millennial students through active learning strategies. Journal of Family \& Consumer Sciences, 105(2), 4449.

Saldana, J. (2011). Fundamentals of Qualitative Research. Cary, GB: Oxford University Press, USA. Retrieved from http://www.ebrary.com

Sengul, S. \& Katranci, Y. (2012). Teaching the subject "sets" with the dissociation and re-association (jigsaw). International Online Journal of Educational Sciences, 4(1). 1-18.

Strayer, J. (2012). How learning in an inverted classroom influences cooperation, innovation and task orientation. Learning Environments Research, 15(2), 171-193. doi:10.1007/s10984-012-9108-4. 
Swaray, R. (2012). An evaluation of a group project designed to reduce free-riding and promote active learning. Assessment \& Evaluation in Higher Education, 37(3), 285-292.

doi:10.1080/02602938.2010.531246

Suh, S. 2006. The effect of using guided questions and collaborative groups for complex problem solving on performance and attitude in a Web-enhanced learning environment. PhD diss., Florida State University, Tallahassee, FL.

U.S. Department of Education, Office of Planning, Evaluation, and Policy Development. (2010). Evaluation of Evidence-Based Practices in Online Learning: A Meta-Analysis and Review of Online Learning Studies, Washington, D.C. Retrieved from http://www2.ed.gov/rschstat/eval/ tech/evidence-based-practices/finalreport.doc

Wadley, D. (2010). Towards a best practice electronic course profile. Teaching in Higher Education, 15(1), 29-43. doi:10.1080/13562510903488121

Wang, L.C., \& Morgan, W. R. (2008). Student Perceptions of using instant messaging software to facilitate synchronous online class interaction in a graduate teacher education course. Journal of Computing in Teacher Education, 25(1), 15-21.

Wetzel, K., Foulger, T.S. \& Williams, M.K. (2008). The evolution of the required educational technology course. Journal of Computing in Teacher Education, 25(2), 67-71.

Yoo, S.J. \& Huang, W.D. (2013). Engaging online adult learners in higher education: Motivational factors impacted by gender, age and prior experiences. Journal of Continuing Higher Education, 61(3), 151-164. doi:10.1080/07377363.2013.836823 